\title{
Influência da época de semeadura na severidade de doenças foliares e na produtividade do milho safrinha
}

\author{
Breno Augusto da Cunha ${ }^{1}$, Mariana Magesto de Negreiros $^{2} \oplus$, Karina Aline Alves $^{3} \oplus$, João Pereira Torres $^{4} \oplus$
}

${ }^{1}$ Mestre em Agronomia pela Universidade Estadual do Norte do Paraná, Universidade Estadual do Norte Do Paraná - Campus Luis Meneghel, Rodovia BR-369 Km 54, Vila Maria, CP 261 - CEP 86360-000, Bandeirantes, Paraná, Brasil; ${ }^{2}$ Doutoranda em Agronomia pela Universidade Estadual de Maringá, Universidade Estadual de Maringá, Programa de Pós-graduação em Agronomia, Av. Colombo, N 5790, Bloco J45, sala 102 - $2^{\circ}$ Piso, CEP - 87020-900, Maringá-PR, Brasil; ${ }^{3}$ Professora Doutora na Universidade Norte do Paraná, UNOPAR - Campus Bandeirantes / PR Avenida Edelina Meneghel Rando, 151 - Vila Macedo, CEP: 86360-000, Bandeirantes-PR, Brasil; ${ }^{4}$ Professor Doutor: João Pereira Torres, Universidade Estadual do Norte do Paraná/UENP, Campus Luiz Meneghel, Bandeirantes/PR, Departamento de Fitopatologia, Universidade Estadual do Norte do Paraná - Campus Luis Meneghel, Departamento De Fitopatologia, Rod. BR-369 Km 54, Vila Maria, CP 261 - CEP 86360 000, Bandeirantes, Paraná, Brasil

Autor para correspondência: Breno Augusto da Cunha (brenoaugusto_2@hotmail.com)

Data de chegada: 18/11/2017. Aceito para publicação em: 05/02/2019.

$10.1590 / 0100-5405 / 188038$

\section{RESUMO}

Cunha, B.A. da; Negreiros, M.M. de; Alves, K.A; Torres, J.P. Influência da época de semeadura na severidade de doenças foliares e na produtividade do milho safrinha. Summa Phytopathologica, v.45, n.4, p.424-427, 2019.

Nas principais áreas produtoras de grãos, o milho tem sido cultivado em duas safras, sendo o milho verão (primeira safra) e o milho safrinha (segunda safra). Desta maneira com a cultura do milho o ano todo no campo, criou-se uma ponte verde, favorecendo o desenvolvimento e a permanência de pragas e doenças. A severidade de doenças podem limitar o desenvolvimento da cultura e comprometer a produtividade. O objetivo deste trabalho foi verificar a influência da época de semeadura na severidade de doenças foliares e na produtividade do milho safrinha, na região norte do Estado do Paraná em duas safras consecutivas, 2015 e 2016. Cercospora zeae-maydis, Pantoea annanatis e Exserohilum turcicun foram as principais doenças foliares observadas nos dois anos consecutivos na região norte do Estado do Paraná. Semeaduras realizadas até 10/03 apresentaram maiores severidades de Puccinia polysora e Pantoea annanatis, enquanto e Exserohilum turcicun foi mais acentuada em semeaduras após 10/03. Para Cercospora zeae-maydis a época de semeadura não demonstrou ter efetiva influência. Maiores índices produtivos foram alcançados quando a semeadura foi realizada precocemente.

Palavras-chave: Zea mays; cultivo sucessivo; severidade; rendimento.

\begin{abstract}
Cunha, B.A. da; Negreiros, M.M. de; Alves, K.A; Torres, J.P. Influence of sowing time on the severity of foliar diseases and winter corn yield. Summa Phytopathologica, v.45, n.4, p.424-427, 2019.

In the main grain producing areas, corn has been grown in two harvest seasons, summer corn (first corn crop) and winter corn (second corn crop). With the corn crop throughout the year in the field, a green bridge was created, favoring the development and the permanence of pests and diseases. The severity of diseases can limit crop development and compromise productivity. The objective of this study was to verify the influence of the time of the sowing season on foliar disease severity and yield of second corn crop in northern Paraná State in two consecutive

harvest seasons, 2015 and 2016. Cercospora zeae-maydis, Pantoea annanatis and Exserohilum turcicun were the main diseases observed in the two consecutive years in the northern region of the state of Paraná. Sowings up to $10 / 03$ showed greater Puccinia polysora and Pantoea annanatis severities, while Exserohilum turcicun was more pronounced in sowings after 10/03. For Cercospora zeae-maydis, the sowing time did not show effective influence. Higher productive rates were achieved when sowing was performed early.
\end{abstract}

Keywords: Zea mays; successive cultivation; severity; yield.

O milho (Zea mays) é um dos cereais mais cultivados no mundo. No Brasil a produção de milho na primeira safra foi de 30,46 milhões de toneladas. O milho de segunda safra apresentou estimativa de produção total de 67,2 milhões de toneladas, cultivadas em 12,1 milhões de hectares, e uma produtividade média de $5.553 \mathrm{~kg} / \mathrm{ha}$. No Estado do Paraná a produtividade média no ano de 2015 foi de 5.091 $\mathrm{kg} / \mathrm{ha}$ enquanto que no ano de 2016 foi de $5456 \mathrm{~kg} / \mathrm{ha}$. (3). O Brasil é o terceiro maior produtor mundial, ficando atrás apenas dos Estados Unidos e da China. O milho possui alta adaptabilidade a diferentes condições de clima e por isso, atualmente é cultivado em todo o mundo e seus subprodutos vão desde alimentação animal e humano até a produção de etanol.

As mudanças no sistema de cultivo do milho, tais como a adoção do plantio direto, irrigação, época de semeadura, tendo primeira safra no verão e safrinha no inverno, cultivo sucessivo, ausência de rotação de culturas associado às condições ambientais brasileiras, aumentou a área de cultivo e fez com que se tivesse milho o ano todo no campo, criando uma ponte verde, prejudicando o vazio fitossanitário, onde 
os patógenos conseguem desenvolver-se e multiplicar-se com maior facilidade, proporcionando o aumento e a severidade das doenças desta cultura.

A ocorrência de patógenos na cultura do milho pode limitar o desenvolvimento quantitativo e qualitativo da planta, proporcionando menor produtividade. Dentre as moléstias mais relevantes que podem limitar o potencial produtivo, destacam-se as doenças foliares.

No Brasil, a época de semeadura do milho é definida, em geral, pela distribuição das chuvas, que influenciam diretamente a oferta de água no solo. $\mathrm{O}$ consumo, de água pelas plantas do milho, durante seu ciclo completo de desenvolvimento se situa entre $500 \mathrm{~mm}$ e 800 $\mathrm{mm}$. O milho safrinha ou segunda safra é amplamente cultivado em sucessão com a cultura de verão, fato esse que o torna dependente da época de colheita da cultura antecessora sendo, em geral, semeado nos meses de janeiro, fevereiro e março. Sua produtividade em relação ao milho de verão ou primeira safra naturalmente é menor, prejudicada por limitações como redução de chuvas, radiação e temperaturas (2).

Portanto, o objetivo deste trabalho foi verificar a influência da época de semeadura na severidade de doenças foliares e na produtividade do milho safrinha, na região norte do Estado do Paraná em duas safras consecutivas, 2015 e 2016.

Os trabalhos sobre a influência da época de semeadura na severidade de doenças foliares e produtividade do milho foram conduzidos em 21 lavouras de milho no ano de 2015, sendo 10 lavouras com semeadura realizada até 10 de março e 11 lavouras com semeadura após 10 de março. No ano de 2016 foram acompanhadas 13 lavouras no total, sendo 7 com semeadura até 10 de março e 6 plantios com semeadura após 10 de março. As lavouras observadas abrangeram cinco municípios situados no norte do Estado do Paraná: Abatiá, Andirá, Bandeirantes, Itambaracá e Santa Mariana.

Em cada lavoura foram demarcadas quatro unidades experimentais, compostas por três linhas do milho com $6 \mathrm{~m}$ de comprimento onde foram avaliadas as variáveis: severidade de doenças foliares e a produtividade.

Para avaliação das doenças, foram amostradas cinco plantas na linha central de cada unidade experimental e avaliada a severidade das doenças nas folhas da espiga, imediatamente uma abaixo e outra acima da espiga. As avaliações deram início quando a cultura se encontrava no estádio fenológico R5 (presença de grãos duros na espiga) Antoniazzi \& Hilario (1). As duas avaliações foram realizadas em intervalos de dez dias. As folhas das plantas não marcadas, identificadas com sintomas de doenças foram levadas ao laboratório de Fitopatologia da Universidade Estadual do Norte do Paraná Campus Luiz Meneghel, para a identificação do patógeno.

A escala usada para quantificar a severidade de ferrugem polissora (Puccinia polysora) foi a desenvolvida por Peterson (10). Para avaliação de cercosporiose (Cercospora zeae-maydis) e helmintosporiose (Exserohilum turcicun), foi usada a escala diagramática proposta por Lazaroto (7). Para a doença mancha branca (Pantoea annanatis) a escala utilizada foi a proposta por Malagi (8).

Para determinar a produção de grãos por hectare, foi feita a colheita manual das três linhas por quatro metros da parcela. As espigas foram debulhadas, os grãos pesados e o teor de água determinado. Os dados de produtividade de grãos foram corrigidos para um teor de $13 \%$ de umidade e expressos em kg.ha ${ }^{-1}$. Os dados foram comparados com auxílio da análise de variância, comparadas por intervalo de confiança de $95 \%$, utilizando o programa Statistica $8.0^{\circledR}$ desenvolvido pela Statsoft.
Com relação à influência das épocas de semeadura na severidade das doenças (Figura 1), os dados demostram claramente uma maior severidade, com significância estatística, para a ferrugem polissora (P. polysora) e mancha branca ( $P$. annanatis) na primeira época. Para Juliatti \& Souza (6), a mancha branca se manifestou apenas nas áreas plantadas no mês de fevereiro, e também relatando menor severidade de ferrugem polissora em semeaduras realizadas tardiamente, corroborando com os resultados encontrados neste trabalho. A ferrugem polissora geralmente ocorre em semeaduras tardias e em regiões de baixa altitude, onde a severidade tende a ser maior devido ao patógeno ser de menor exigência em termos de umidade para o progresso da doença (5). A helmintosporiose (E. turcicun), aparece estatisticamente de forma mais importante na segunda época. A cercosporiose $(C$. zeae-maydis) foi registrada de forma equivalente nas duas épocas de semeadura.

Nas áreas amostradas não foram encontradas as doenças foliares comumente diagnosticas em lavouras do milho no Brasil, como: ferrugem branca (Physopella zeae), ferrugem comum (Puccinia sorghi), antracnose (Colletotrichum graminicola), mancha de diplodia (Stenocarpella macrospora), mosaico comum e enfezamentos (Figura 1).

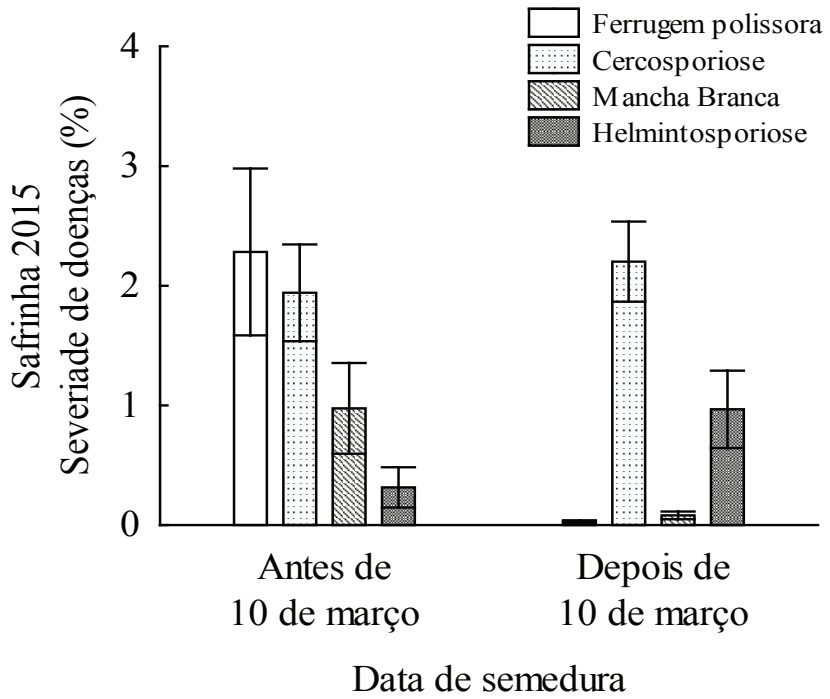

Barras verticais: diferença mínima significativa por intervalo de confiança (IC95\%).

Figura 1. Severidade média de doenças foliares na cultura do milho na região norte do Estado do Paraná, em função da época de semeadura, no ano de 2015.

A segunda safra de milho no ano de 2015 mostrou-se bastante favorável ao desenvolvimento da cultura. A ocorrência das chuvas se deu de forma bastante satisfatória, tanto em termos quantitativos quanto em distribuição ao longo do período da estação de cultivos, não havendo praticamente nenhum período mais significativo de estiagem. Também as médias de temperaturas se mantiveram dentro dos padrões amplamente favoráveis ao desenvolvimento da cultura do milho. Observou-se temperaturas máximas na faixa dos $30^{\circ} \mathrm{C}$ e mínimas acima dos $10^{\circ} \mathrm{C}$. A umidade relativa do ar manteve-se em torno dos $80 \%$ ao longo da estação, sofrendo queda significativa apenas no mês de agosto, já no final da safra, reflexo da distribuição de chuvas e da temperatura. Esses dados implicaram também em boas condições para 
o desenvolvimento de patógenos foliares.

A época de semeadura é um dos fatores determinantes para a exploração do potencial produtivo na cultura do milho. Exatamente por poder explorar as melhores condições de ambiente, temperaturas e umidade do solo, ao longo da estação de cultivo. Para isso o Zoneamento climático para o milho, relatado por Shioga (11), fixou como época mais adequada à semeadura do milho na região norte do Estado do Paraná até 10 de março, podendo se estender além, porém sob condições já menos propícias, com maiores riscos e sujeito a menores produtividades. Os dados desta pesquisa vêm ao encontro dessas recomendações, corroborando de forma estatisticamente significativa maiores produtividades nas primeiras épocas de semeadura, até 10 de março, 9,5 t/ha, contra aproximadamente 7,5 t/ha nas semeaduras após 10 de março, Figura 2. Vários trabalhos demonstraram que, conforme se atrasa a semeadura do milho, a partir da época recomendada para certa região, ocorre queda na produção de grãos em função da variação nos fatores climáticos, tais como: precipitação, radiação solar e temperatura $(4,9,13)$.

Na Figura 3, estão os dados de severidade média para as três doenças registradas na segunda safra de 2016.

A mancha branca aparece de forma equivalente nas duas épocas de semeadura. A cercosporiose foi registrada apenas na primeira época, enquanto helmintosporiose apenas na segunda época. Os dados mostram diferenças acentuadas, demostrando que, no caso das doenças foliares, altamente dependentes das condições ambientais, cada ano apresenta as suas especificidades. Enquanto que em 2015 a ferrugem polissora mostrou presença importante na primeira época, em 2016 não foi constatada. A cercosporiose, igualmente importante nas duas épocas na safra de 2015 , nesta safra de 2016 foi registrada apenas na primeira época e com severidade bem menos significativa. A mancha branca estatisticamente equivalente nas duas épocas nesta safra de 2016, na segunda safra de 2015 foi significativa apenas na primeira época.

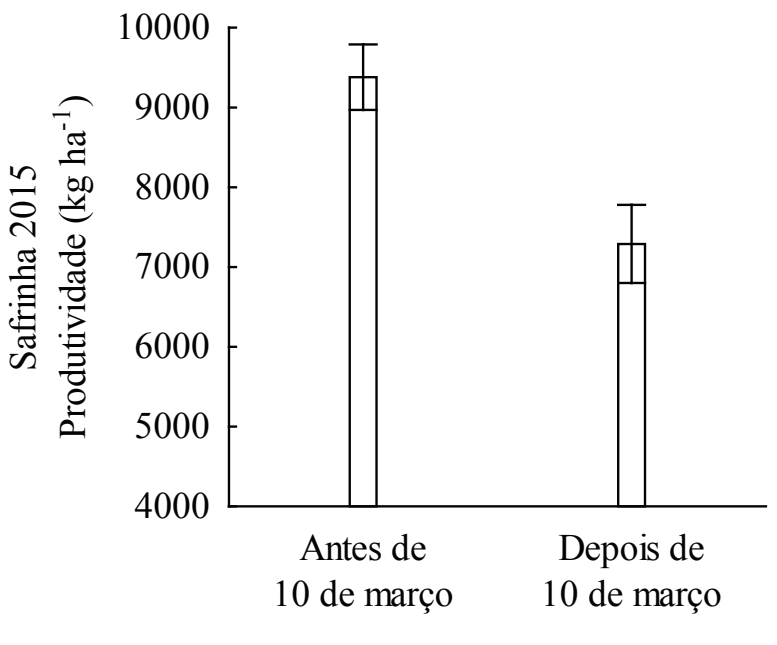

\section{Data de semeadura}

Barras verticais: diferença mínima significativa por intervalo de confiança (IC95\%).

Figura 2. Produtividade da cultura do milho na região norte do Estado do Paraná, em função da época de semeadura, no ano de 2015.

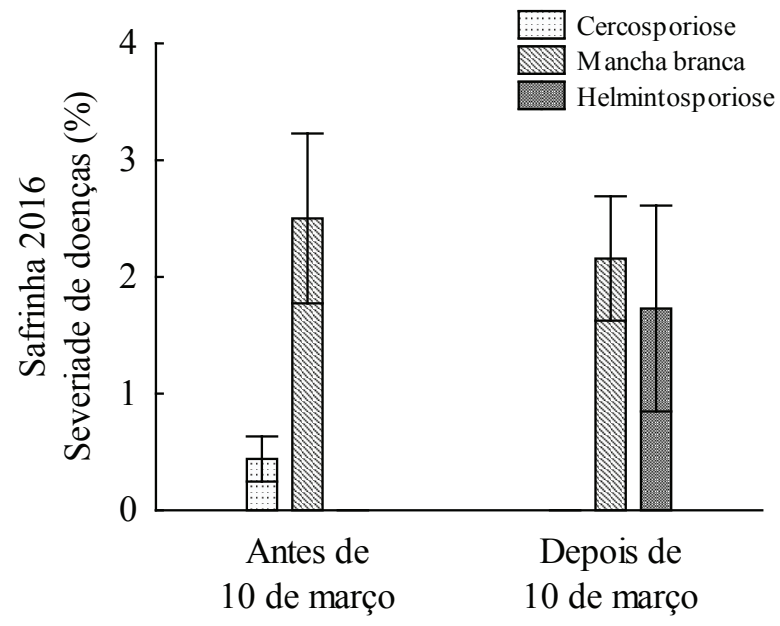

Data de semedura

Barras verticais: diferença mínima significativa por intervalo de confiança (IC95\%).

Figura 3. Severidade média de doenças foliares na cultura do milho na região norte do Estado do Paraná, em função da época de semeadura, no ano de 2016.

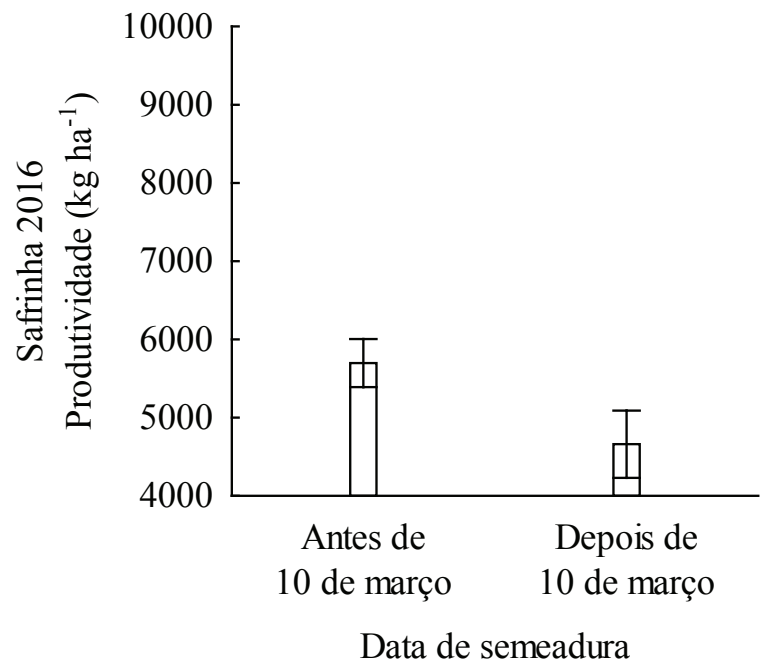

Barras verticais: diferença mínima significativa por intervalo de confiança (IC95\%).

Figura 4. Produtividade na cultura do milho na região norte do Estado do Paraná, em função da época de semeadura, no ano de 2016.

E por fim a severidade da helmintosporiose, importante nesta safra de 2016 apenas na segunda época de semeadura, em 2015 foi registrada nas duas épocas, ainda que com mais significância na segunda época. Praticamente as mesmas doenças registradas por Shioga (12), para a mesma safra de milho, segunda safra do ano de 2016, na estação de Cambará/PR. Essas diferenças, aparentes contradições, indicam que o manejo das doenças foliares na cultura do milho é complexo, e a 
intercorrência das doenças mostra-se variável de ano para ano, sempre relacionadas às condições climáticas.

Os registros dos dados de produtividade para a segunda safra do ano de 2016 estão assinalados na Figura 4.

Na comparação de épocas de semeadura, Figura 4, a safra 2016 apresentou a mesma tendência comparativamente à de 2015. Ou seja, a primeira época de semeadura, até 10 de março, a produtividade mostrou-se superior estatisticamente, em relação à segunda época, posterior a 10 de março.

A produtividade foi de 5,8 e $4,8 \mathrm{t} / \mathrm{ha}$ aproximadamente, respectivamente, para a primeira e segunda época. As diferenças de produtividade entre as duas safras deve-se claramente às diferenças climáticas. No entanto a superioridade em termos de produtividade para a primeira época de semeadura mostrou-se muito consistente nas duas safras avaliadas, o que demonstra o quanto o zoneamento climático para a cultura do milho, quando considerado, pode contribuir para a estabilidade da produção da cultura.

\section{REFERÊNCIAS}

1. Antoniazzi, N.; Hilario, J.M.N. Reação de híbridos de milho à Cercospora Zeae-Maydis. In: Congresso Nacional de Milho e Sorgo, 27., 2008, Londrina. Anais. Londrina: IAPAR, 2008. p.208.

2. Cessa, R.M.A.; Souza, F.R. Estresse hídrico e o manejo de irrigação na cultura do milho. Cultivar: Grandes Culturas, Pelotas, v.178, p.10-12, 2014.

3. Companhia Nacional do Abastecimento. Acompanhamento da safra brasileira: V. 4 - Safra 2016/17- N. 12 - Décimo segundo levantamento, 2017. Disponível em: < https://www.conab.gov.br/info-agro/safras/graos/ boletim-da-safra-de-graos>. Acesso em: 21 out. 2017.
4. Costa, A.F.S. Influência das condições climáticas no crescimento e desenvolvimento de plantas de milho (Zea mays $L$.), avaliadas em diferentes épocas de plantio. 1994. 109p. Tese (Doutorado em Fitotecnia) - Universidade Federal de Viçosa, Viçosa.

5. Grigolli, J.F.J. Doenças do milho safrinha. Tecnologia e produção: Milho safrinha e culturas de inverno. Mato Grosso do Sul: Fundação MS, 2013. p.121-133.

6. Juliatti, F.C.; Souza, R.M. Efeito de épocas de plantio na severidade de doenças foliares e produtividade de híbridos de milho. Bioscience Journal, Uberlândia, v.21, n.1, p.103-112, 2005.

7.Lazaroto, A.; Santos, I.; Konflanz, V.A.; Malagi, G.; Camochena, R.C. Escala diagramática para avaliação de severidade da helmintosporiose comum em milho. Ciência Rural, Santa Maria, v.42, n.12, p.1-7, 2012.

8. Malagi, G.; Dos Santos, I.; Camochena, R.C.; Moccellin, R. Elaboração e validação da escala diagramática para avaliação da mancha branca do milho. Revista Ciência Agronômica, Ceará, v.42, n.3, p.797-804, 2011.

9. Noldin, J.A. Rendimento de grãos, componentes de rendimento e outras características de planta de três cultivares de milho em duas épocas de semeadura. 1985. 134p. Tese (Mestrado em Agronomia/Fitotecnia) Universidade Federal do Rio Grande do Sul, Porto Alegre.

10. Peterson, R.F.; Campbell, A.B.; Hannah, A.E. A diagrammatic scale for estimating rust intensity on leaves and stems of cereals. Canadian Journal of Research, Ottawa, v.26, n.5 , p. 496-500, 1948.

11. Shioga, P.S.; Gerage, A.C.; Araújo, P.M.; Bianco, R.; Custódio, A.A.P. Avaliação estadual de cultivares de milho segunda safra 2015. Londrina: IAPAR, 2015. 101p. (IAPAR Boletim Técnico, 86).

12. Shioga, P.S.; Gerage, A.C.; Araújo, P.M.; Bianco, R.; Barros, A.S.R. Custódio, A.A.P. Avaliação estadual de cultivares de milho segunda safra 2016. Londrina: IAPAR, 2016. 52p. (IAPAR Boletim Técnico, 88).

13. Souza, F.R.S. Estabilidade de cultivares de milho (Zea mays $L$.) em diferentes épocas e locais de plantio em Minas Gerais. Lavras, 1989. 64p. Dissertação (Mestrado em Genética e Melhoramento de Plantas) - Escola Superior de Agricultura de Lavras, Lavras. 